\title{
Functional analysis of Arabidopsis and maize transgenic lines overexpressing the ADP-ribose/NADH pyrophosphohydrolase, AtNUDX7
}

\author{
ELIZABETH NJUGUNA ${ }^{1,2}$, GRIET COUSSENS ${ }^{1,2}$, PIA NEYT $^{1,2}$, STIJN AESAERT $^{1,2}$, VERONIQUE STORME ${ }^{1,2}$, \\ KIRIN DEMUYNCK ${ }^{1,2}$, HANNES VANHAEREN ${ }^{1,2}$, STIJN DHONDT ${ }^{1,2}$, YOLAINE VAN HAVER $^{1,2}$, LINUS PAUL LI, $^{1,2}$ \\ DIRK INZÉ ${ }^{1,2}$, HILDE NELISSEN ${ }^{1,2}$ and MIEKE VAN LIJSEBETTENS*,1,2 \\ ${ }^{1}$ Department of Plant Biotechnology and Bioinformatics, Ghent University and \\ ${ }^{2}$ Center for Plant Systems Biology, VIB, Gent, Belgium
}

\begin{abstract}
The conserved poly(ADP-ribosyl)ation (PAR) pathway consists of three genetic components that are potential targets to modulate the plant's energy homeostasis upon stress with the aim to improve yield stability in crops and help secure food supply. We studied the role of the PAR pathway componentADP-ribose/NADH pyrophosphohydrolase (AtNUDX7) in yield and mild drought stress by using a transgenic approach in Arabidopsis thaliana and maize (Zea mays). Arabidopsis AtNUDX7 cDNA was overexpressed in Arabidopsis and maize by means of the constitutive Cauliflower Mosaic Virus 35S promoter and the strong constitutive Brachypodium distachyon $\mathrm{p} B d E F 1 \alpha$ promoter, respectively. Overexpression of AtNUDX7 in Arabidopsis improved seed parameters that were measured by a novel, automated method, accelerated flowering and reduced inflorescence height. This combination of beneficial traits suggested that AtNUDX7 overexpression in Arabidopsis might enhance the ADP-ribose recycling step and maintain energy levels by supplying an ATP source in the poly(ADP-ribosyl)ation energy homeostasis pathway. Arabidopsis and maize lines with high, medium and low overexpression levels of the AtNUDX7 gene were analysed in automated platforms and the inhibition of several growth parameters was determined under mild drought stress conditions. The data showed that the constitutive overexpression of the Arabidopsis AtNUDX7 gene in Arabidopsis and maize at varying levels did not improve tolerance to mild drought stress, but knocking down AtNUDX7 expression did, however at the expense of general growth under normal conditions.
\end{abstract}

KEY WORDS: seed yield, flowering time, water deficit, mild drought stress, constitutive promoter

\section{Introduction}

The poly(ADP-ribosyl)ation (PAR) pathway (Fig. 1) is a posttranslational protein modification process, activated upon singleor double-stranded DNA breaks, in which ADP-ribose subunits from nicotinamide adenine dinucleotide (NAD+) are covalently attached to target proteins mediated by the poly(ADP-ribose) polymerase enzyme (PARP). PARP activity can be reversed by a poly(ADP-ribose) glycohydrolase enzyme (PARG) generating free ADP-ribose molecules that can be degraded into adenosine monophosphate (AMP) and ribose-5-phosphate by an ADP-ribosespecific Nudix hydrolase enzyme (D'Amours et al., 1999). The
AMP can be utilized to replenish the ATP and NAD+, leading to maintenance of cellular homeostasis (Rossi et al., 2002). The free ADP-ribose, produced during the reverse degradation of protein-bound mono- or poly-(ADP-ribose), is highly reactive and can mono-(ADP-ribosyl)ate proteins nonenzymatically, thereby altering or eliminating their function. Thus, the ADP-ribose py-

\footnotetext{
Abbreviations used in this paper: AMP, adenosine monophosphate; bar, bialaphos resistance; $\mathrm{NAD}^{+}$, nicotinamide adenine dinucleotide; nptII, neomycin phosphotransferase II; NUDX or Nudix, nucleoside diphosphate linked to some x moiety; PARG, poly(ADP-ribose) glycohydrolase; PARP, poly(ADP-ribose) polymerase; PAR, poly(ADP-ribosyl)ation; PAT, phosphinothricin acetyl transferase.
}

*Address correspondence to: Mieke Van Lijsebettens. Technologiepark 71, 9052 Gent, Belgium. Tel: +32 93313800 . Fax: +32 93313809. E-mail: milij@psb.vib-ugent.be - web: https://www.ugent.be and http://www.psb.ugent.be - iD https://orcid.org/0000-0002-7632-1463

Supplementary Material (two tables and two figures) for this paper is available at: https://doi.org/10.1387/ijdb.180360mv 


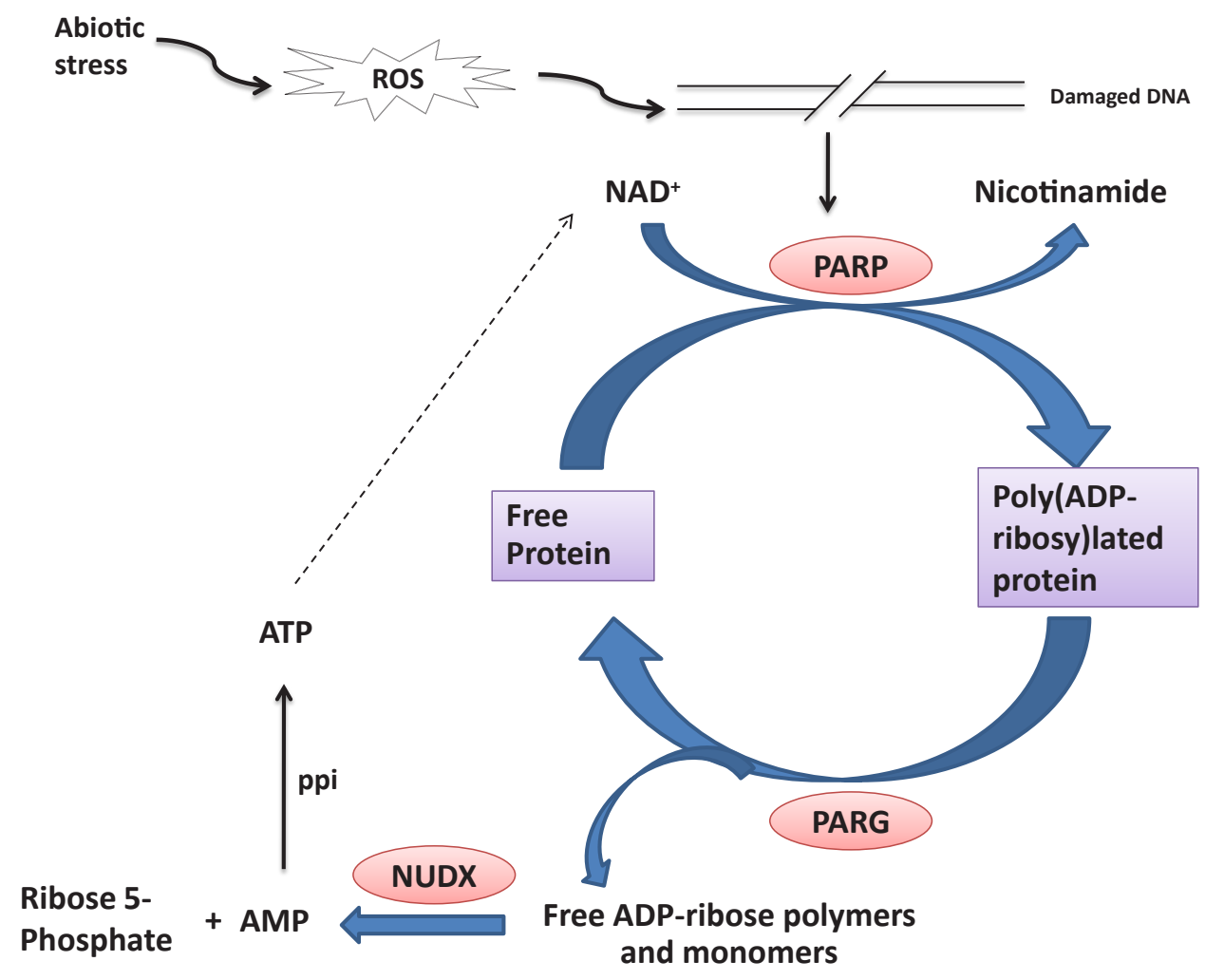

Fig. 1. Role of the poly(ADP-ribosyl)ation pathway in stress response and energy homeostasis. Reactive oxygen species (ROS) produced during abiotic stress may lead to a single- or double-stranded break in the DNA, triggering poly(ADP-ribose) polymerase (PARP) activity. PARP catalyzes the formation of a poly(ADP-ribose) chain on free proteins by sequential addition of $A D P$ ribose molecules from nicotinamide adenine dinucleotide $\left(N A D^{+}\right)$. Poly(ADP-ribose) glycohydrolase (PARG) catalyzes the catabolism of the poly(ADP-ribose) chain into free ADPribose monomers and polymers that are hydrolyzed to adenosine monophosphate (AMP) and ribose 5-phosphate by the activity of the ADP-ribose-specific Nudix hydrolase (NUDX) enzyme. AMP is an available precursor of adenosine triphosphate (ATP) that can be used to replenish the $N A D^{+}$pool.

rophosphohydrolase activity of the Nudix hydrolase proteins is very important in regulating the levels of free ADP-ribose and maintaining protein integrity in the cell.

The PAR pathway has been broadly studied in animals; it plays a key role in DNA repair, genotoxic stress response, chromatin structure, transcription regulation, apoptosis, and cell cycle activities (D'Amours et al., 1999; Kim et al., 2005). In plants, PAR has been implicated in several physiological processes and described as an important regulatory mechanism modulating responses to abiotic and biotic stresses, such as oxidative stress (Amor et al., 1998; Ogawa et al., 2008; Ishikawa et al., 2009), DNA damage (Doucet-Chabeaud et al., 2001; Song et al., 2015), drought stress (De Block et al., 2005), osmotic stress (Li et al., 2011), immune response (Adams-Phillips et al., 2010; Ishikawa et al., 2010; Feng et al., 2015; Song et al., 2015), and also in growth (Schulz et al., 2012, 2014). PARP and PARG proteins (Fig. 1) are multifunctional in plants as well, and are involved in abiotic stress tolerance, DNA damage response, plant growth, and biotic stress response. Indeed, down-regulation of the PARP gene in Brassica napus (rapeseed) and Arabidopsis thaliana enhanced tolerance to a broad range of abiotic stresses (De Block et al., 2005). Arabidopsis parp mutants are hypersensitive to DNA damage induced by bleomycin and mytomycin (Song et al., 2015). Inhibition of Arabidopsis PARP enhanced plant growth by promoting the leaf cell number (Schulz et al., 2014), perturbed innate immune responses to microbe-associated molecular patterns, such as fl22 and elf18 (Adams-Phillips et al., 2010), and compromised basal defense responses (Feng et al., 2015; Song et al., 2015). The Arabidopsis parg 1 mutants were more sensitive to cell damage under osmotic and oxidative stresses ( $\mathrm{Li}$ et al., 2011), enhanced DNA damage and cell death upon treatment with bleomycin (Zhang et al., 2015), and accelerated the onset of disease symptoms upon infection with Botrytis cinerea (AdamsPhillips et al., 2010).

The Nudix-encoding (NUDX) genes (Fig. 1) might be an alternative for modulating energy homeostasis in plants as opposed to the PARP and PARG genes. Nudix hydrolases consist of a large family of conserved proteins in viruses, archaea, bacteria, and eukaryotes, characterized by the highly conserved Nudix box, GX5EX7REUXEEXGU, with $U$ being a bulky, hydrophobic amino acid, usually lle, Leu, or Val (Bessman et al., 1996). Almost all the major substrates for these enzymes are nucleoside diphosphates linked to some other moiety, $x$, hence the acronym "Nudix". They have a broad substrate range, including: dinucleoside polyphosphates, ADP-ribose, NADH, nucleotide sugars, or ribo- and deoxyribonucleoside triphosphates, coenzyme $A$, mRNA cap, and FAD (Bessman et al., 1996; Dunn et al., 1999; Ogawa et al., 2005, 2008). Accumulation of these substrates is potentially toxic to the cell and their intracellular levels need to be precisely regulated. Therefore, a role for Nudix hydrolases in sanitizing or modulating the accumulation of these metabolites was postulated (Bessman et al., 1996).

The genome of the model plant Arabidopsis thaliana contains 28 genes coding for putative Nudix hydrolases (Yoshimura and Shigeoka, 2015). These proteins are classified into three types according to their predicted subcellular localization: cytosol, mitochondrion, and chloroplast. Arabidopsis Nudix hydrolases targeted to the cytosol include AtNUDX1 to AtNUDX11, AtNUDX25, and AtDCP2 (Ogawa et al., 2005; Yoshimura and Shigeoka, 2015). AtNUDX1 is the functional homolog of the Escherichia coli MutT (Ogawa et al., 2005) because it plays an important protective role against oxidative DNA and RNA damage in Arabidopsis cells through sanitization of their precursor pool in the cytosol (Yoshimura et al., 2007). However, the Atnudx1 mutant plants 
did not exhibit any noticeable changes in their phenotype under normal or stressful conditions (Kraszewska, 2008); hence it remains to be shown whether the AtNUDX1 gene perturbations have any physiological impact on Arabidopsis plants.

Cytosolic AtNUDX2, AtNUDX6, AtNUDX7, and AtNUDX10 have a pyrophosphohydrolase activity toward both ADP-ribose and NADH (Ogawa et al., 2005). Overexpression of AtNUDX2 in Arabidopsis enhanced tolerance to oxidative stress due to maintenance of $\mathrm{NAD}^{+}$and ATP levels by nucleotide recycling from free ADP-ribose molecules. However, AtNUDX2 is not the predominant ADP-ribose pyrophosphohydrolase in Arabidopsis, because its downregulation resulted only in a slight reduction $(10 \%)$ of the ADP-ribose pyrophosphohydrolase activity in the transgenic plants, indicating that other enzymes with higher

A

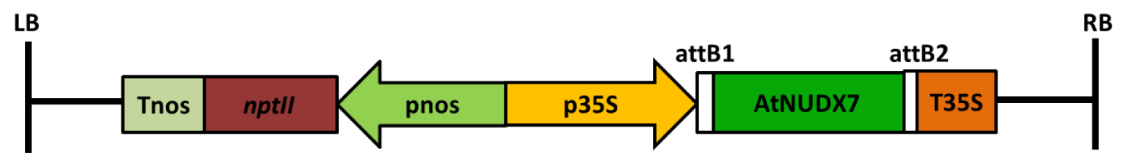

B

C

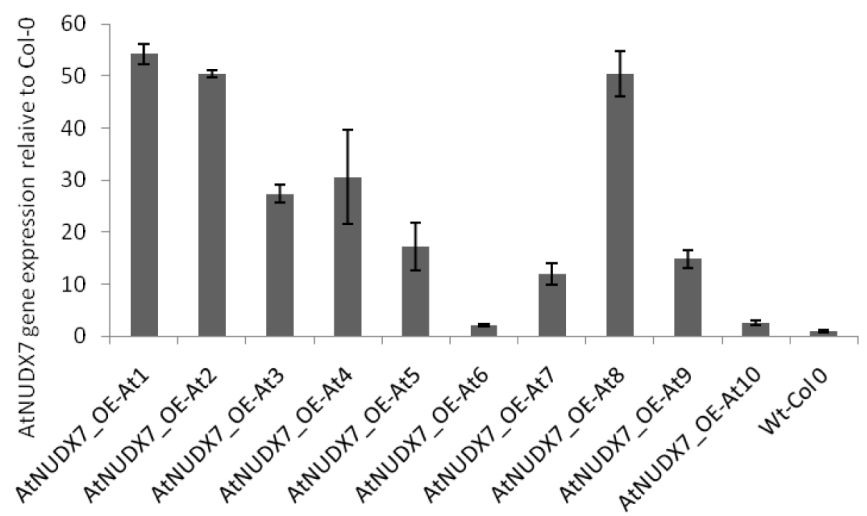

D

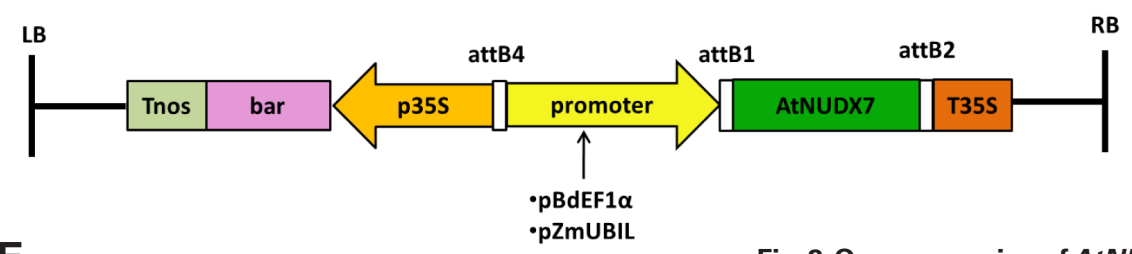

$\mathbf{E}$

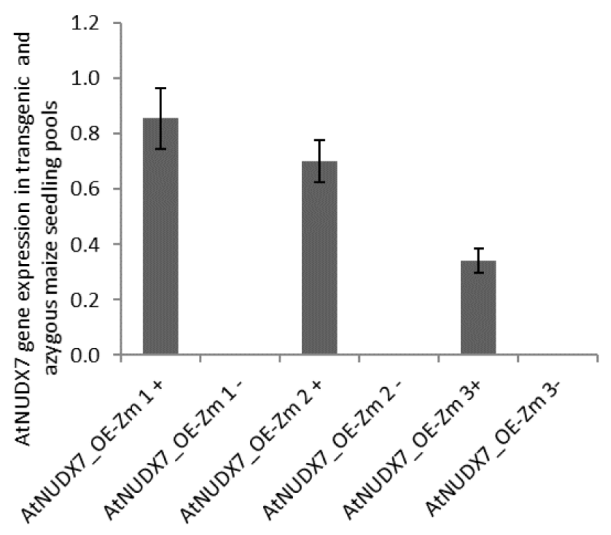

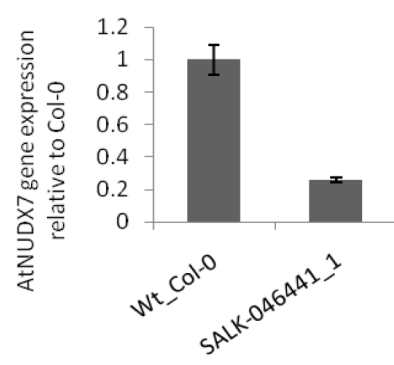

ADP-ribose pyrophosphohydrolase activity may exist in Arabidopsis cells (Ogawa et al., 2009). AtNUDX6 modulates NADH rather than ADP-ribose metabolism and significantly impacts the Arabidopsis plant immune response as a positive regulator of the NONEXPRESSOR OF PATHOGENESIS-RELATED GENES1 (NPR1)-dependent salicylic acid signaling pathways (Ishikawa et al., 2010). AtNUDX7 is induced by multiple stresses and is involved in both biotic and abiotic stress responses (Bartsch et al., 2006; Jambunathan and Mahalingam, 2006; Ge et al., 2007, 2008; Adams-Phillips et al., 2008; Ishikawa et al., 2009; Jambunathan et al., 2010). AtNUDX7 showed a preferential activity for ADPribose and NADH when expressed in E. colicells (Ge et al., 2007). AtNUDX7 has been proposed as the predominant ADP-ribose and NADH pyrophosphohydrolase in Arabidopsis cells, because Atnudx 7 loss-of-function mutant plants showed approximately $76.9 \%$ and $46.9 \%$ significantly reduced pyrophosphohydrolase activities towardADP-ribose and $\mathrm{NADH}$, respectively, in comparison to the levels in wild-type plants (Ishikawa et al., 2009). Overexpression of AtNUDX7 enhanced tolerance to paraquatinduced oxidative stress, due to the restoration of $\mathrm{NAD}^{+}$and ATP levels upon activation of poly(ADP-ribosyl)ation reaction under oxidative stress, whereas knocking down AtNUDX7led to the opposite observation. Hence, AtNUDX7 regulates the defense mechanisms against oxidative DNA damage via modulation of the PAR reaction (Ishikawa et al., 2009).

Here, AtNUDX7 was overexpressed in Arabidopsis and maize plants and analysed for seed yield, yield-associated parameters, and mild drought stress, which are highly desired
Fig. 2. Overexpression of AtNUDX7in Arabidopsis and maize. (A) Scheme of the T-DNA construct for overexpression of the AtNUDX7 gene in Arabidopsis. The components consist of the left border (LB), nopaline synthase terminator (Tnos), neomycin phosphotransferase II selection marker (nptll), nopaline synthase promoter (pNos), Cauliflower Mosaic Virus $35 S$ promoter (p35S), AtNUDX7 gene, Cauliflower Mosaic Virus 35S terminator (T35S), Gateway attachments sites (attB1 and attB2), and right border (RB). (B) AtNUDX7 gene expression relative to Col-0 in 10 independent Arabidopsis p35S::AtNUDX7 lines by qPCR $(\mathrm{n}=4)$. (C) AtNUDX7 gene expression relative to Col-0 in the Atnudx7-1 mutant line (SALK-046441_1) by qPCR $(\mathrm{n}=3$ ). (D) Scheme of the T-DNA construct for overexpression of the AtNUDX7 gene in maize. The components consist of left border (LB), nopaline synthase terminator (Tnos), bar selection marker (bar), Cauliflower Mosaic Virus $35 S$ promoter (p35S), Brachypodium distachyon promoter ( $\mathrm{pBdEF1 \alpha )}$ or maize ubiquitin promoter (pZmUBIL), AtNUDX7 gene, Cauliflower Mosaic Virus 35S terminator (T35S), Gateway attachments sites (attB1, attB2, and attB4), and right border (RB). (E) AtNUDX7 gene expression in three independent T1 maize lines measured in pools of transgenic $(+)$ and pools of azygous (-) seedlings for the pBdEF1 $\alpha$-AtNUDX7 construct by qPCR (n $=5)$. Error bars indicate standard deviation. 
TABLE 1

SUMMARY OF THE ARABIDOPSIS AND MAIZE TRANSGENIC LINES

\begin{tabular}{|c|c|c|c|c|}
\hline Arabidopsis genotype & T3 Arabidopsis line & T-DNA loci & Fold change & Functional assay \\
\hline \multirow[t]{10}{*}{ p35S::AtNUDX7 } & AtNUDX7_OE-At1 & 1 & 54 & Seed yield/yield-associated parameters and mild drought stress \\
\hline & AtNUDX7_OE-At2 & 1 & 50 & \\
\hline & AtNUDX7_OE-At3 & 1 & 27 & \\
\hline & AtNUDX7_OE-At4 & 1 & 31 & \\
\hline & AtNUDX7_OE-At5 & 1 & 17 & \\
\hline & AtNUDX7_OE-At6 & 1 & 2 & \\
\hline & AtNUDX7_OE-At7 & 1 & 12 & \\
\hline & AtNUDX7_OE-At8 & 1 & 50 & \\
\hline & AtNUDX7_OE-At9 & 1 & 15 & \\
\hline & AtNUDX7_OE-At10 & 1 & 3 & \\
\hline Atnud $x 7-1$ mutant & SALK-046441-1 & 1 & -4 & Seed yield/yield-associated parameters and mild drought stress \\
\hline Maize genotype & T1 maize line & T-DNA loci & AtNUDX7 expression level & \\
\hline \multirow[t]{6}{*}{ pBdEF1a::AtNUDX7 } & AtNUDX7_OE-Zm1 & 1 & 0.9 & Mild drought stress \\
\hline & AtNUDX7_OE-Zm2 & 1 & 0.7 & \\
\hline & AtNUDX7_OE-Zm3 & 1 & 0.3 & \\
\hline & AtNUDX7_OE-Zm4 & 1 & 0.0005 & \\
\hline & AtNUDX7_OE-Zm5 & 1 & 0.0001 & \\
\hline & AtNUDX7_OE-Zm6 & 1 & 0.01 & \\
\hline \multirow[t]{5}{*}{$p Z m U B I L:: A t N U D X 7$} & AtNUDX7_OE-Zm7 & 1 or 2 & 0.002 & \\
\hline & AtNUDX7_OE-Zm8 & 1 & 0.001 & \\
\hline & AtNUDX7_OE-Zm9 & 1 & 0.005 & \\
\hline & AtNUDX7_OE-Zm10 & 1 & 0.0008 & \\
\hline & AtNUDX7_OE-Zm11 & 1 & 0.003 & \\
\hline
\end{tabular}

Shaded lines were functionally analysed.

traits in the light of the ongoing climate change and reduced arable land.

\section{Results and Discussion}

\section{Overexpression of the AtNUDX7 gene in Arabidopsis and maize}

The full-length cDNA of the AtNUDX7 gene (AT4G12720) was overexpressed in Arabidopsis thaliana Columbia (Col-0) accession under the control of the constitutive Cauliflower Mosaic Virus 35S promoter using the plant Gateway expression vector pK2GW7 (Karimi et al., 2007), which carries a neomycin phosphotransferase II (nptII) selectable marker gene (Fig. 2A). After floral dip transformation, T0 transgenic Arabidopsis plants were selected on kanamycin-containing media at high density plating and, subsequently, T3 lines with a single-locus homozygous T-DNA insertion were identified (Table 1). Two-week-old T3 seedlings of p35S::AtNUDX7 lines and Col-0 control plants were used in a quantitative (q)PCR expression analysis. High, medium, and low overexpression levels of AtNUDX7 were observed in 10 independent transgenic $p 35 S:: A t N U D X 7$ lines in comparison to the Col-0 control, ranging between 2-fold to 50 -fold (Fig. 2B, Table 1; supplementary Table S1). A loss-of-function mutant line, which we designated Atnudx7-1 (SALK-046441), with a T-DNA insertion in exon 1 of the AtNUDX7gene, in the Col-0 background (Bartsch et al., 2006; Jambunathan and Mahalingam, 2006; Ge et al., 2007; Adams-Phillips et al., 2008; Ishikawa et al., 2009; Jambunathan et al., 2010; Ogawa et al., 2016), was verified for its T-DNA insertion position, homozygous T-DNAinsertion, AtNUDX7gene expression, and was used as a negative control (Fig. 2C). A subset of the Arabidopsis lines overexpressing AtNUDX7with higher overexpression levels, ranging between 17- and 54-fold (Table 1), values much higher than those in previously analysed lines (Ishikawa et al., 2009), and the Atnudx7-1 mutant line (Table 1) were subsequently used to study seed yield parameters, yield-associated parameters, flowering time, and inflorescence height.

The AtNUDX7full-length cDNA was overexpressed in the maize B104 inbred line with the strong constitutive Brachypodium distachyon promoter, $\mathrm{pBdEF1} \alpha$ (Coussens et al., 2012), or the constitutive maize ubiquitin promoter, pZmUBIL (Christensen etal., 1992), in the monocot multisite Gateway expression vector pBbm42GW7 (Karimi et al., 2013) that carries the bialaphos resistance (bar) selection maker gene (Fig. 2D). The AtNUDX7 overexpression construct was transformed with the EHA101 supervirulent Agrobacterium strain (Hood et al., 1986) and the Agrobacterium-mediated transformation method (Coussens et al., 2012; Anami et al., 2013). The transgenic T0 plants were backcrossed to the B104 control maize plants, generating T1 lines with a hemizygous T-DNA insertion. The T1 maize lines were analysed for bar gene segregation by means of a phosphinothricin acetyl transferase (PAT) assay and for T-DNA intactness with PCR; lines with an intact transgene and a single-locus T-DNAinsertion were used in subsequent experiments. For qPCR expression analyses, five pools of three PAT-positively segregating T1 seedlings containing the T-DNA and five pools of three PAT-negatively segregating T1 seedlings without T-DNAwere sampled. Three independent transgenic $p B d E F 1 \alpha:: A t N U D X 7 \mathrm{~T} 1$ maize lines with high, medium, and low expression levels of the AtNUDX7 gene were retained for functional analysis (Fig. 2E). Lines containing the $p Z m U B I L:: A t N U D X 7$ overexpression construct had generally much lower expression levels than lines driven by the $p B d E F 1 \alpha$ promoter and, hence, were not functionally analysed (Table 1). The $p B d E F 1 \alpha:: A t N U D X 7$ maize lines with varying expression levels, i.e. AtNUDX7_OE-Zm1, AtNUDX7_OE-Zm2, 
and AtNUDX7_OE-Zm3 (Table 1), were self-fertilized, upscaled to generate T3 homozygous maize lines, and further used in a mild drought stress experiment.

\section{Improved seed yield parameters and early flowering time upon overexpression of AtNUDX7 in Arabidopsis}

The Arabidopsis NUDX7 protein restores the NAD+ and ATP levels upon activation of the PAR reaction under abiotic and biotic stresses (Ishikawa et al., 2009; Ogawa et al., 2016), which might improve seed yield stability upon expression modulation. Hence, we investigated seed yield parameters in the two high overexpression (OE) lines, AtNUDX7_OE-At1 and AtNUDX7_OE-At2, the medium OE line, AtNUDX7_OE-At3, the low OE line AtNUDX7_OE-At5, the Atnudx7-1 mutant line (Salk-046441_1), and the Col-0 control line (Table 1). Total seed weight, seed number per 10 siliques, seed size, mass per seed, in addition to the yield-associated parameters, flowering time, number of leaves at bolting, and inflorescence height were determined according to Van Daele et al. (2012). The seed yield and yieldassociated parameters determined for the p35S::AtNUDX7 OE lines, the Atnudx7-1 mutant line, and the Col-0 control line are presented and summarized (Figs. 3,4; supplementary Table S2).

The high OE line AtNUDX7_OEAt2 had a significantly increased total seed weight per plant and a significant increase in number of seeds per 10 siliques (seed number) when compared to Col-0, with a seed mass and size comparable to those of Col-0. A significant increase in seed number, seed size, and mass per seed was visible in the moderate OE line, AtNUDX7_OE-At3, but not in the total seed weight. The total seed weight was determined by weighing the total seed harvested when fully mature and dried, whereas imaging was used for determination of seed number and seed size. Mass per seed was calculated as described (Materials and Methods). The difference in methodology to obtain the seed parameters might be the reason for the lack in increase in the total seed weight in spite of the increase in seed number, seed size, and mass per seed in AtNUDX7_OE-At3. In the low OE line AtNUDX7_OE-At5, the total seed weight per plant had also significantly increased, whereas seed number, seed size, and mass per seed remained unchanged (Figs 3 and 4; supplementary Table S2). In a replicate experiment, improved seed yield parameters were measured in the same three AtNUDX7OE_At2, AtNUDX7 OE_At3, and AtNUDX7 OE_At5 lines, but were more pronounced in the high and medium $O E$ lines than in the low OE line.

The high OE lines AtNUDX7_OE-At1 and AtNUDX7_OE-At2, and the moderate OE line AtNUDX7_OE-At3 were significantly early flowering, had a reduced number of leaves at bolting, and
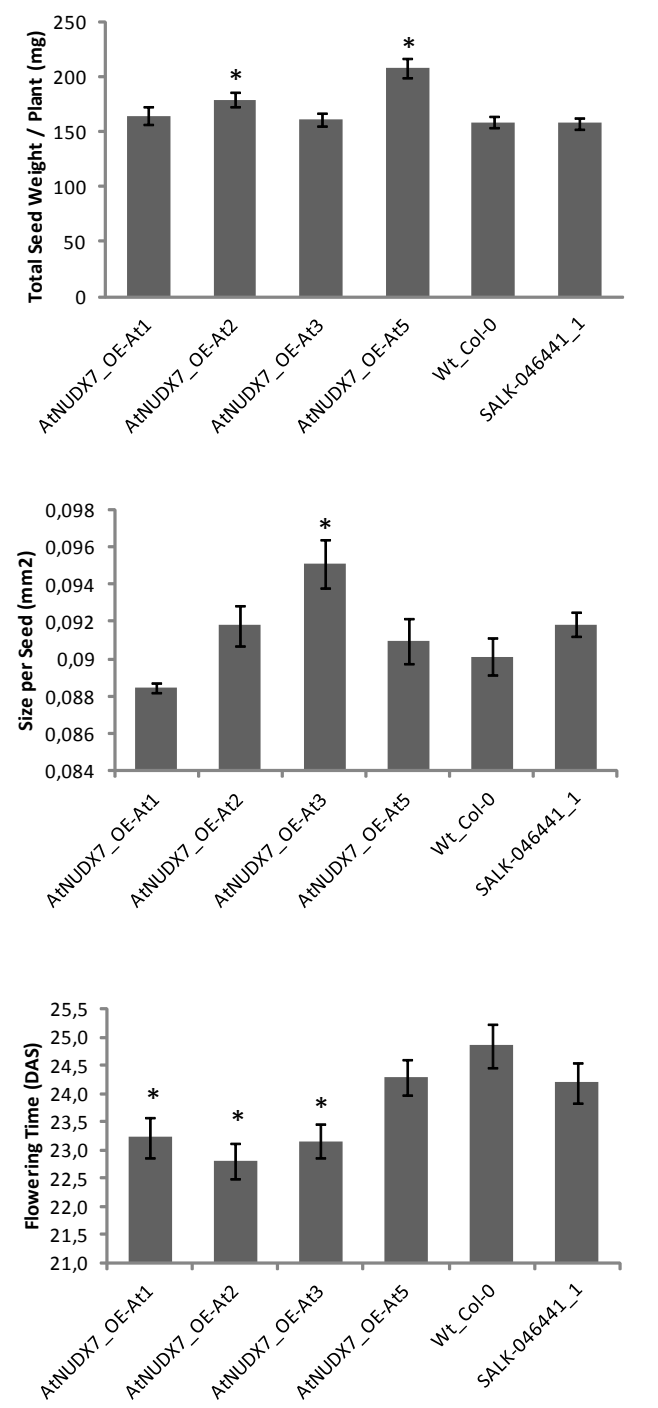
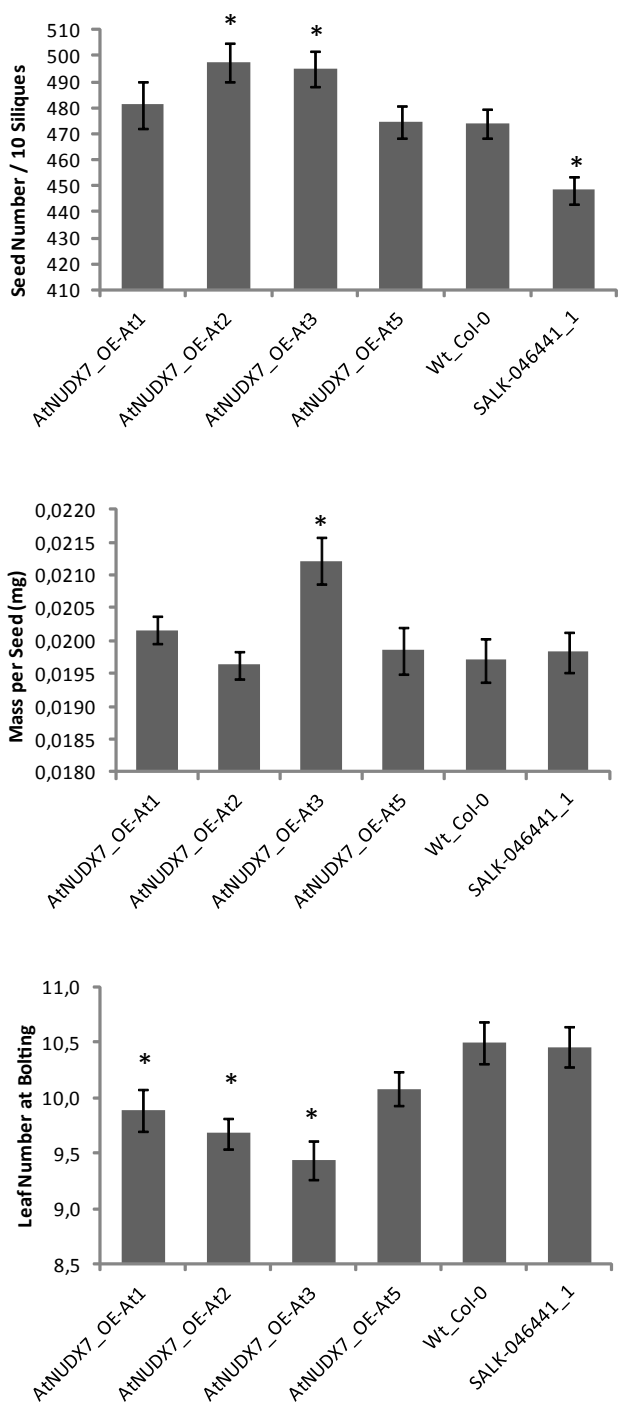

Fig. 3. Seed yield and flowering time parameters of the T3 p35S::AtNUDX7 Arabidopsis overexpression lines, Atnudx 7-1 mutant line (SALK-046441_1), and Col-0 line. Error bars indicate standard error of the mean. Significant differences compared to Col-0 are marked with asterisks $(\mathrm{P}<0.01$, Student's t- test). 

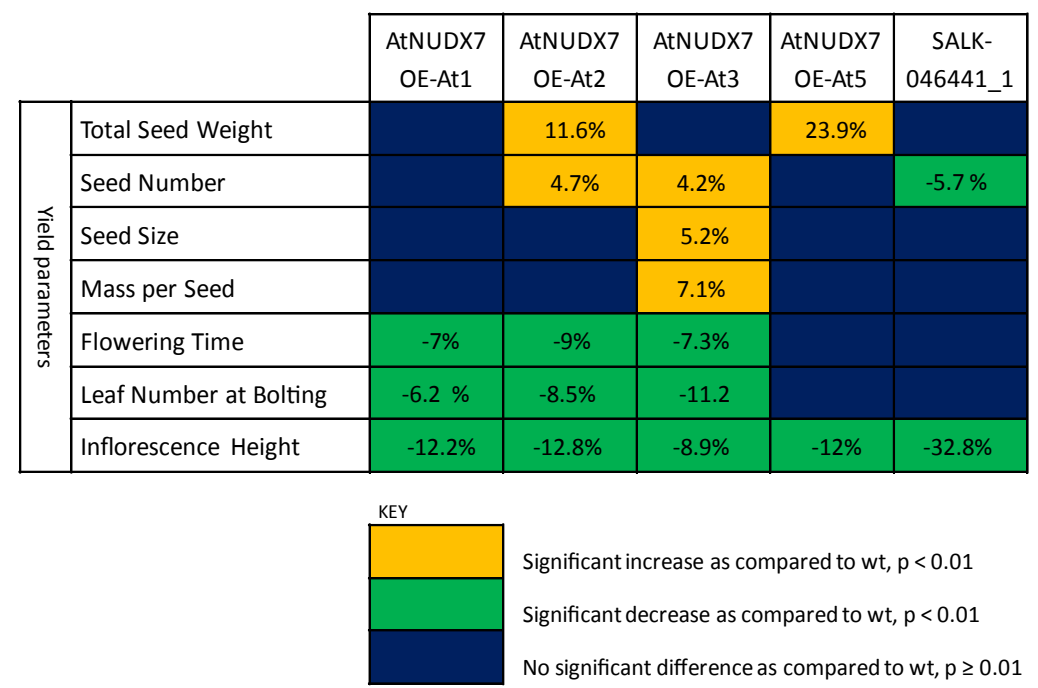

Fig. 4. Heat map of seed yield and flowering time parameters in four T3 p35S::AtNUDX7 overexpression lines and the Atnudx7-1 mutant line (SALK046441_1). Percentage increase or reduction in the parameters compared to the wild-type (wt) control is indicated. Significant differences determined with the Student's t-test.

\section{al., 2006; Jambunathan and Mahalingam, 2006).}

Here, we show that overexpression of the AtNUDX7gene increases the seed yield parameters in Arabidopsis. The data suggest that enhancement of the ADP-ribose recycling step and maintenance of the energy levels by supplying an ATP source in the PAR energy homeostasis pathway throughout the plant's life cycle might be beneficial for seed production. Hence, under greenhouse conditions, maintenance of energy homeostasis by overexpression of AtNUDX7might overcome energy restrictions atcertain stages during plant development or during subtle environmental fluctuations, resulting in

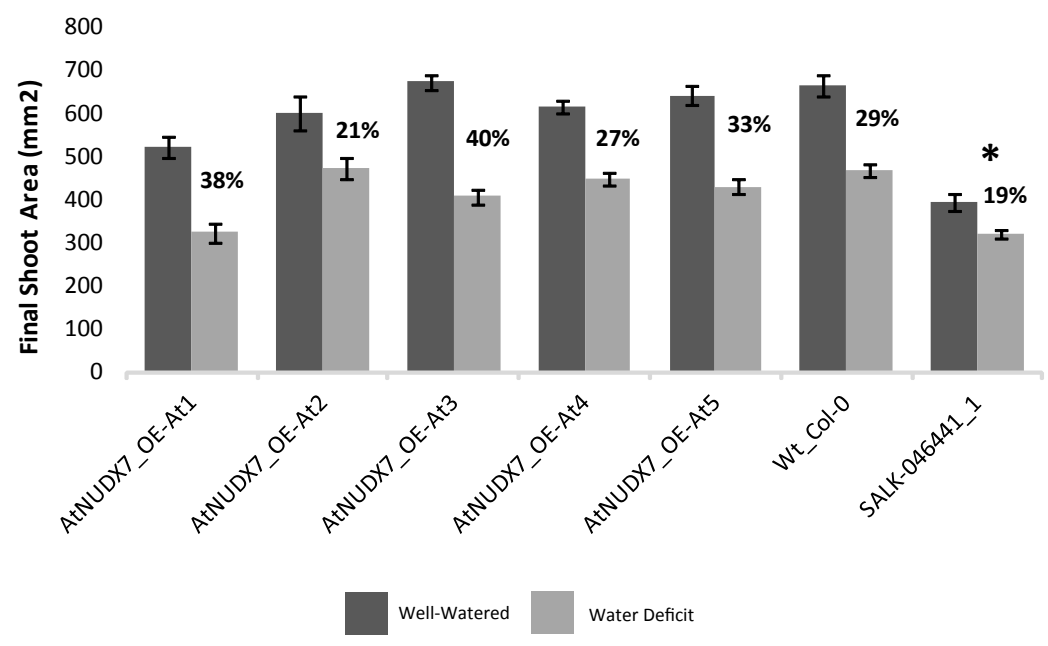

Fig. 5. Final shoot area of fiveT3 p35S::AtNUDX7Arabidopsis overexpression lines, the Atnudx7-1 mutant line (SALK-046441_1), and the Col-0 control line under well-watered and water deficit conditions. The percentage of the final shoot area reduction upon the water deficit treatment is indicated per genotype. Error bars mark standard error of the mean $(\mathrm{n}=16)$. The asterisk indicates significant difference in the final shoot area between the Atnudx7-1 mutant line and the Col-0 control line upon the water deficit treatment $\mathbb{P}=0.0244$, two-way analysis of variance with custom hypothesis Wald tests, corrected for multiple testing). improved seed size and/or number. Our data are in line with previous reports that showed that preservation of the energy homeostasis through the PARP inhibition or PARG modulation of the PAR pathway under stress and nonstress conditions resulted in enhanced plant growth (De Block et al., 2005; Li et al., 2011; Schulz et al., 2012, 2014). In conclusion, our data indicate that the PAR pathway and its genetic component, AtNUDX7, might contribute to the complex trait of seed yield. In addition to improved seed yield parameters, AtNUDX7 overexpression lines were early flowering and had reduced inflorescence height, all three being beneficial traits in cereal agronomy. Whether overexpression of AtNUDX7accelerates the flowering time directly through its role in energy homeostasis or indirectly by induction of other pathways that affect flowering time is unclear and might be an interesting topic for future research.

\section{Evaluation of the AtNUDX7 overexpression Arabi- dopsis lines under mild drought stress}

Mild drought stress treatment has been proposed to be a better test for superior growth performance during water deficit conditions than severe drought stress treatment that activates water saving and plant survival mechanisms (Skirycz et al., 2011). Thus, a mild drought stress experiment was set up on an automated weighing, imaging and watering (WIWAM) high-throughput phenotyping platform according to established protocols (Skirycz et al., 2011; Clauw et al., 2015). Two irrigation conditions were selected in the experiment, namely a well-watered control and a mild soil water deficit treatment, for which plants were watered up to a set soil water content based on daily target weight calculations using a gravimetric method. Seven Arabidopsis genotypes, comprising the two high overexpression lines, AtNUDX7_OE-At1 and AtNUDX7_OE-At2, the two medium overexpression linesAtNUDX7_OE-At3 and AtNUDX7_OE-At4, the low overexpression line AtNUDX7_OE-At5, the Atnudx7-1 mutant line (SALK-046441_1), and the Col-0 control line were analysed (Table 1). The final projected shoot area of the well-watered and water deficit-treated plants was determined on the last day of the experiment (Fig. 5).

Shoot growth has been described as a sensitive, relevant, and easily measured phenotype for assessing stress tolerance over a wide range of stress levels (Claeys et al., 2014). In this experiment, rosette area reduction was used as an indicator of mild drought stress response. A $20 \%$ to $40 \%$ reduction in shoot area was observed in plants growing under mild drought stress conditions when compared to the well-watered plants at the end of the experiment. Although the reduction in the final shoot area varied in the OE AtNUDX7 lines in comparison to that of the Col-0 control upon water deficit, none of the differences was statistically significant (Fig. 5). The Atnudx7-1 mutant line had a significantly lower reduction in shoot area of $10 \%$ compared to Col-0 control plants under water deficit treatment $(P$ $=0.0244$, two-way analysis of variance with custom 
hypothesis Wald tests, corrected for multiple testing with Sidak step-down), indicating tolerance to mild drought stress (asterisk, Fig. 5). However, the Atnudx7-1 mutant plants were smaller than the wild type under normal conditions (Fig. 5).

Previously, modulation of the PAR pathway via downregulation of the PARP gene expression in Arabidopsis and rapeseed had been found to give rise to plants with tolerance to a broad range of abiotic stresses, including drought (De Block et al., 2005). The drought stress treatment in that report was more severe than in this study; the plants were grown for 7 to 8 days in vitro, were then transferred to soil, and 8 to 9 days after transfer water was withheld for 6 days, whereafter they were rewatered once, and finally scored 7 to 10 days later, when control plants turned yellow. Metadata analysis with the Genevestigator software (Zimmermann et al., 2004) revealed that the AtNUDX7gene is induced in several severe drought stress studies in Arabidopsis. Mild and severe drought stress responses are regulated by different mechanisms: whereas during mild drought stress plants maintain growth despite the reduced resources, during severe drought stress, survival mechanisms are triggered, such as stomatal closure to limit water loss, reduction of shoot growth, diversion of carbon and energy to storage, and biosynthesis of protective compounds, all of which lead to a penalty in plant growth and yield (Skirycz et al., 2011; Claeys and Inzé, 2013). Thus, we speculate that the mild water deficit conditions used in our study investigates a trait different to that tested under the more severe drought stress conditions (De Block et al., 2005).

\section{Evaluation of the AtNUDX7 overexpression maize lines under mild drought stress}

Previously, we had shown that an Arabidopsis full-length cDNA can be functional in maize and, instead of looking for its ortholog, it might be used to modulate a conserved pathway (Nelissen et al., 2012). Hence, the full-length cDNA of the AtNUDX7 gene was cloned behind the Brachypodium distachyon $\mathrm{pBdEF} 1 \alpha$ promoter, transformed in maize, and high, medium, and low overexpression lines were analysed for their response to mild drought stress in an automated platform. The irrigation of plants was based on the daily measurement of the gravimetric soil water content and its adjustment to preset values according to the requirements of the treatments: well-watered control and soil water deficit. The length of the 4th leaf was measured daily from the base of the plant to the leaf tip and from its appearance until maturity and was used to determine the leaf growth rate. As soon as the 4th leaf stopped growing, its blade weight, blade and sheath weights, blade width, total leaf area, and also fresh and dry weights of the seedlings were measured. Three T3 homozygous maize lines, AtNUDX7_OE-Zm1, AtNUDX7_OE-Zm2, and AtNUDX7_OE-Zm3, with a high, medium and low overexpression level of the AtNUDX7 gene, respectively, and the B104 control line were analysed. Upon water deficit, the
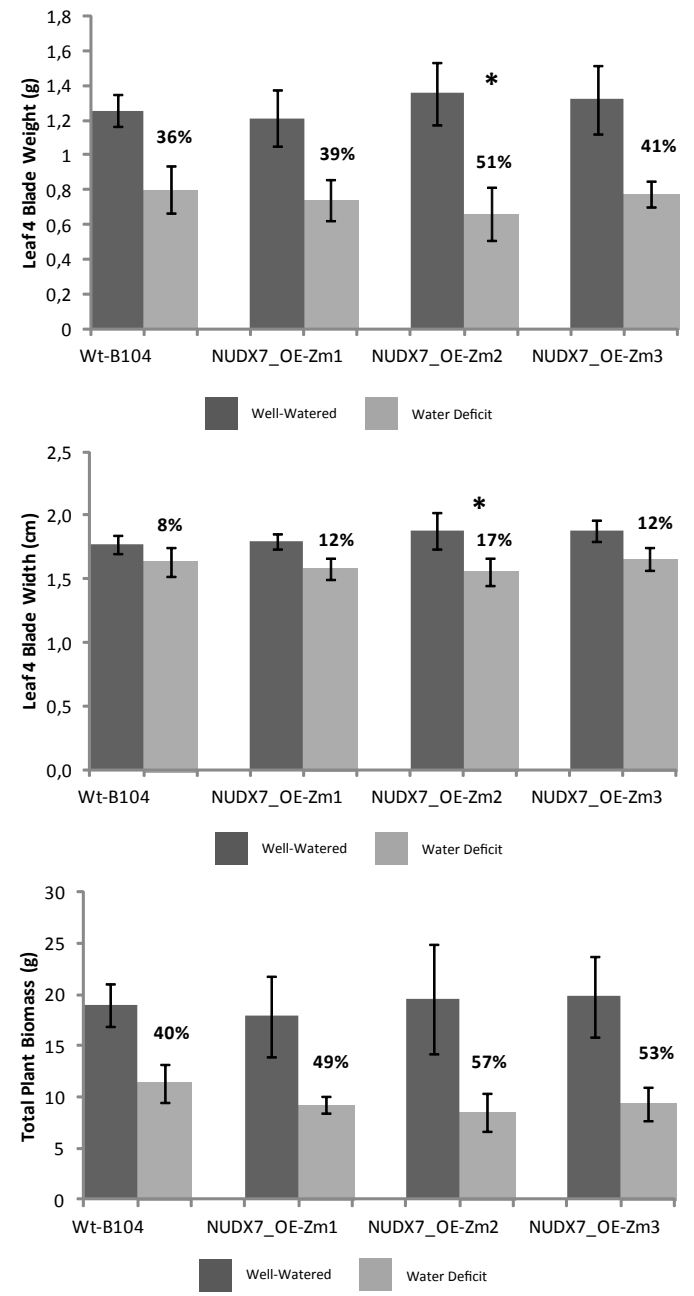
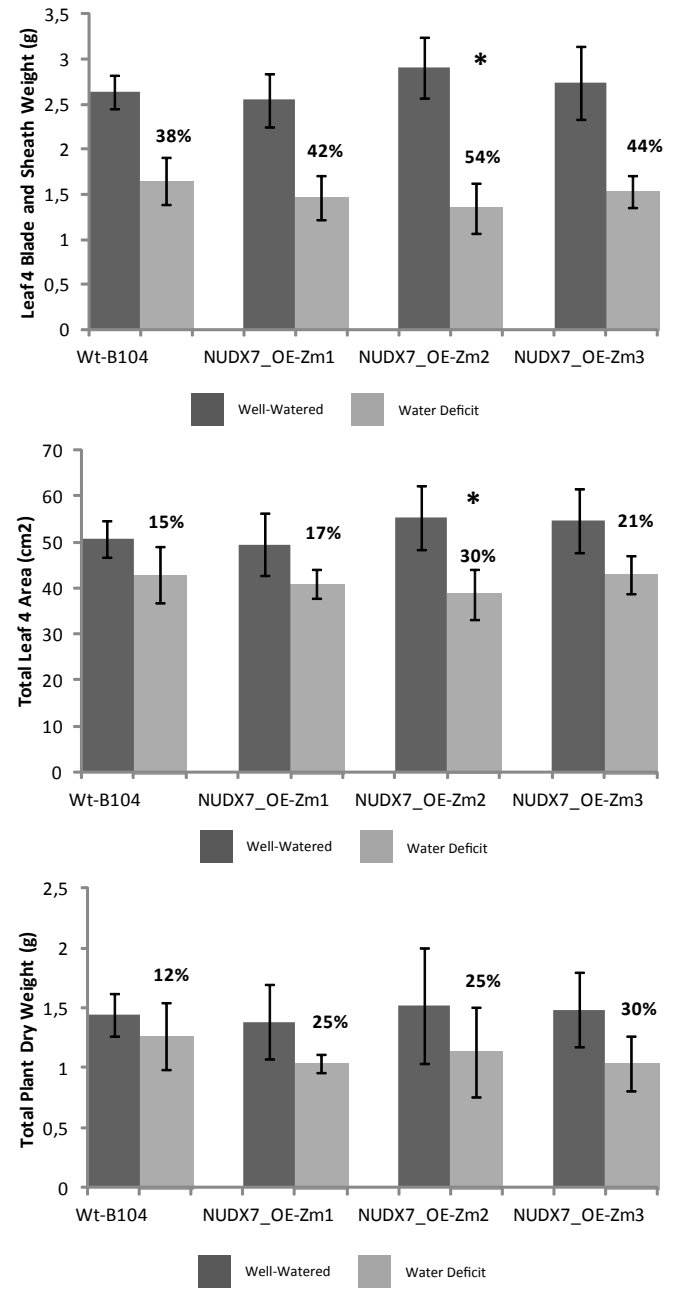

Fig. 6. Endpoint parameters measured in the mild drought stress experiment to compare the homozygous

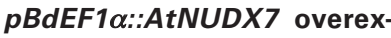
pression T3 maize lines, AtNUDX7_OE-Zm1, AtNUDX7_ OE-Zm2, and AtNUDX7_OEZm3 with the B104 control maize under well-watered and water deficit conditions. The percentage reduction of each parameter upon the water deficit treatment is indicated per genotype. The asterisks mark significantly higher reductions of leaf 4 blade weight, blade and sheath weight, blade width, and total area of the AtNUDX7_OEZm2 line upon water deficitstress in comparison to the B104 control $(P=3.17 E-03,5.55 E-04,8.65 E-$ 03 , and 7.93E-04 respectively, two-way analysis of variance with custom hypothesis Wald tests, corrected for multiple testing). Error bars indicate standard deviation $(\mathrm{n}=12)$. 
TABLE 2

\section{PERCENTAGE OF REDUCTION IN LEAF 4 GROWTH OF T3 MAIZE LINES TRANSGENIC FOR pBdEF1 $\alpha:: A t N U D X 7$ UPON WATER DEFICIT TREATMENT}

\begin{tabular}{lc} 
T3 maize lines & Reduction in leaf $\mathbf{4}$ growth \\
\hline AtNUDX7_OE-Zm1 & $19.6 \%$ \\
AtNUDX7_OE-Zm2 & $25.2 \%$ \\
AtNUDX7_OE-Zm3 & $22.6 \%$ \\
Wt-B104 & $20.3 \%$ \\
\hline
\end{tabular}

high and low overexpression maize lines, AtNUDX7_OE-Zm1 and AtNUDX7_OE-Zm3, respectively, had a higher reduction percentage in all the parameters measured than the B104 wild type, although not statistically significant. However, the leaf 4 blade weight, blade and sheath weights, blade width, and total leaf area of the medium overexpression line AtNUDX7_OE-Zm2 were respectively 15\%, $16 \%, 9 \%$ and $15 \%$ significantly more reduced under water deficit conditions than those of the B104 control (asterisks, Fig. 6), whereas the reduction in plant biomass and plant dry weight under water deficit of the AtNUDX7_OE-Zm2 line was not statistically different from that in the B104 maize control (Fig. 6). Additionally, the reduction percentage in leaf 4 growth for the three AtNUDX7 overexpression maize lines did not significantly differ from that of the B104 control upon the water deficit treatment (Table 2). The water deficit experiment on the automated platform was done in three repeats; in the previous two experiments, with fewer individuals per genotype, most parameters were not significantly different from the B104 maize control.

Therefore, our data indicate that overexpression of the AtNUDX7 gene in maize does not confer tolerance to mild drought stress. The use of a drought stress-inducible promoter for AtNUDX7overexpression might be more appropriate than the strong constitutive promoter used, which would allow the modulation of the PAR energy salvage pathway only on a need basis. In addition, the Arabidopsis-derived AtNUDX7 gene might not function properly in maize, because it diverges from its close maize homologs, GRMZM2G101693 and GRMZM2G175816, that have longer $\mathrm{N}$-terminal extensions on their protein sequence, possibly affecting their ADP-ribose substrate affinity (supplementary Fig. $\mathrm{S} 1)$. Preliminary experiments indicated that overexpression of the maize homologs of AtNUDX7 in maize and Arabidopsis did not confer tolerance to mild drought stress, suggesting that they probably do not participate in the mild drought stress response.

In conclusion, the different levels of constitutive overexpression of the Arabidopsis AtNUDX7gene in Arabidopsis and also in maize did not result in a mild drought stress tolerance phenotype. However, downregulation of AtNUDX7 resulted in mild drought stress tolerance under water deficit but growth under normal conditions was reduced. We hypothesise that the AtNUDX7 component of the PAR pathway might only be involved in severe drought response mechanisms, in analogy with the PARP component (De Block et al., 2005), and that it might be worthwhile to test it in future experiments.

\section{Materials and Methods}

\section{Plant material and growth conditions}

Transgenic lines and a loss-of-function mutant line (SALK-046441) were derived from Arabidopsis thaliana (L.) Heynh. accession Col-0 and were grown either in tissue culture rooms, growth rooms, or under greenhouse conditions. Tissue culture room conditions were $21^{\circ} \mathrm{C}$ temperature, $16 \mathrm{~h}$ light/8 $\mathrm{h}$ darkness, and $80 \mu \mathrm{mol} \mathrm{m}^{-2} \mathrm{~s}^{-1}$ light intensity, whereas the growth room conditions were $22^{\circ} \mathrm{C}$ temperature, $55 \%$ relative humidity, $100 \mu \mathrm{molm}^{-2} \mathrm{~s}^{-1}$ light intensity, and 16-h light/8-h dark regime, and greenhouse conditions were $21^{\circ} \mathrm{C}$ temperature, $55 \%-60 \%$ relative humidity, $100 \mu \mathrm{molm}^{-2} \mathrm{~s}^{-1}$ light intensity, and 16-h light/8-h dark regime. In vitro plants in the tissue culture room were grown on full-strength Murashige and Skoog (MS) medium (Murashige and Skoog, 1962) supplemented with $1 \%(\mathrm{w} / \mathrm{v})$ sucrose, whereas plants in the growth room and greenhouse were cultured on trays containing jiffy soil (sphagnum peat moss).

The B104 maize genotypes (Hallauer et al., 1997) were grown either in growth rooms or under greenhouse conditions. The maize growth room conditions were $24^{\circ} \mathrm{C}$ temperature, $55 \%$ relative humidity, $230 \mu \mathrm{E} \mathrm{m}^{-2} \mathrm{~s}^{-1}$ light intensity, and 16-h light/8-h dark regime, whereas the greenhouse conditions were $22-26^{\circ} \mathrm{C}$ temperature, $45 \%$ relative humidity, $300 \mu \mathrm{E} \mathrm{m}^{-2} \mathrm{~s}^{-1}$ light intensity, and $16 \mathrm{~h}$ light/8-h dark regime. Maize seeds were sown on trays containing jiffy soil (sphagnum peat moss) and placed in the maize growth room, where the seedlings grew for 2 to 3 weeks, whereafter they were transferred to larger soil pots and placed in the greenhouse until maturity.

\section{Arabidopsis and maize transformation, PAT assay, and T-DNA integrity check}

Arabidopsis plants were transformed with the AtNUDX7overexpression construct by means of the Agrobacterium tumefaciensfloral dip transformation method (Clough and Bent, 1998). Immature embryos of the B104 maize inbred line were transformed with the AtNUDX7 overexpression construct according to Coussens et al. (2012), with the exception that 2,4-D had been replaced by dicamba $(3.32 \mathrm{mg} / \mathrm{l})$. The T-DNA intactness was determined by PCR analysis with forward primers binding to either the $p B d E F 1 \alpha$ or the pZmUBIL promoter (Coussens et al., 2012) and reverse primers binding to the T33S terminator region to confirm that a complete AtNUDX7 gene had been inserted. Transgenic plant materials were selected with the bar marker gene, of which the activity was identified by detection of the PAT protein with the PAT assay kit (AgraStrip $\AA L L$ Strip test kit; Romer Labs ${ }^{\circledR}$, Union, MO, USA), according to the manufacturer's instructions.

\section{qPCR expression analysis}

RNA was isolated from 2-week-old Arabidopsis T3 seedlings (consisting of four pools of five seedlings for the AtNUDX7 overexpression lines and three pools of five seedlings for the Atnudx7-1 mutant line) and from 10- to 12-day-old division zone tissue of the 4th leaf of T1 maize (consisting of five pools of three transgenic $(+)$ and the same for the azygous (-) maize seedlings) with the RNeasy Plant Mini Kit (Qiagen) and the cDNA prepared with the SuperScript III First-Strand Synthesis System for reverse-transcription PCR (Invitrogen), according to the manufacturers' protocols. qPCR experiments were carried out in a LightCycler480 RealTime SYBR Green PCR System (Roche) and all reactions were done in three technical replicates. For the Arabidopsis samples, the expression levels were normalized to the reference genes SAND (AT2G28390), PP2A (AT1G13320), and YLS8 (AT5G08290), whereas for the maize samples, the expression levels were normalized to the reference genes $18 \mathrm{SrRNA}$ and EF1 (GenBank accession X00794.1 and NM_001112117.1, respectively).

\section{Measurement of seed yield and yield-associated parameters}

Seed yield parameters were measured as described (Van Daele et al., 2012). To determine the total seed weight, 25 plants per genotype were grown for approximately 3.5 months under greenhouse conditions until the seeds were fully mature and dried; all the seeds were harvested, cleaned, and weighed. The mean seed weight per plant was then established and indicated as the total seed weight per plant. For the seed size, the seed area of 200-400 seeds per plant of 10 plants per genotype was measured by applying an image analysis macro (supplementary Fig. S2) 
on the ImageJ software (http://imagej.nih.gov/ij/). To determine whether an increase or decrease in the seed size was accompanied by an increase or decrease in mass, the mass per seed of the genotypes was assessed by dividing the mass of seeds by their total number. More precisely, the mass of 200-400 seeds per plant and 10 plants per genotype was obtained by weighing the seeds on a scale and the respective number of seeds counted through the image analysis macro on the ImageJ software. First, the scale of the pictures was manually set in the ImageJ software. With a single macro (supplementary Fig. S2), all pictures with a JPG file extension in a selected folder were automatically opened and cropped. Next, the background was removed by adjusting the Brightness/Contrast to a minimum of 0 and a maximum of 72 . Subsequently, the images were saved and processed to binary values to measure the projected seed area with a size from 0.02 to infinity and a circularity of $0.00-1.00$. Hereafter, the number of seeds per 10 siliques, termed seed number, was counted from 16 plants per genotype grown under greenhouse conditions for 2 months until the plants had reached maturity. Seeds from 10 yellow or brown unopened siliques from the middle of the main inflorescence of each plant were harvested and counted by means of the image analysis macro on the Image J software as described above. To determine the flowering time and number of leaves at bolting, 25 plants per genotype were grown under growth room conditions. Flowering time was calculated as the difference between the first day of appearance of the flower bud and the day of sowing and indicated as days after sowing (DAS) as unit. The number of leaves (excluding the cotyledons) at bolting was counted at the first day of flower bud appearance. To determine the inflorescence height, the length of a fully stretched primary inflorescence was recorded of 16 plants per genotype, grown under greenhouse conditions for 2 months until the plants had reached maturity and no increase in length was observed anymore.

\section{Mild drought stress experiment in an automated platform for Arabidopsis}

The experiment was set up on an automated WIWAM XY platform (www. wiwam.com) for high-throughput phenotyping according to established protocols (Skirycz et al., 2011; Clauw et al., 2015). The WIWAM system is placed in an Arabidopsis growth room with $21^{\circ} \mathrm{C}$ temperature, $55 \%$ relative humidity, 16 -h day/8-h night regime, and $100 \mu \mathrm{mol} \mathrm{m} \mathrm{m}^{-2} \mathrm{~s}^{-1}$ light intensity. Seeds were stratified for 2 days before sowing in pots containing 80 to $90 \mathrm{~g}$ soil. Seeds of the same age were used for all genotypes and watering was carried out daily at the same time to avoid biases. Sixteen seedlings per genotype were grown for the well-watered treatment and 16 seedlings per genotype for the water deficit treatment. Soil water content of the well-watered control plants was set at a constant value of $2.19 \mathrm{~g}$ water per $g$ dry soil during the entire experiment. For the mild drought stress treatment, plants were grown for 9 days under well-watered conditions; then the daily target soil water content was reduced and maintained at $1.19 \mathrm{~g}$ water per $\mathrm{g}$ dry soil until the end of the experiment (21 days after sowing). Pots were randomized on the WIWAM platform on a daily basis. On the last day, the final shoot area was determined by processing the rosette images.

\section{Mild drought stress experiment in an automated platform for maize}

The AtNUDX7 overexpression maize lines were analysed in an automated platform for their response to mild drought stress by daily weighing and watering of the soil pots. A soil water content of $2.40 \mathrm{~g}$ and $1.00 \mathrm{~g}$ water per $g$ dry soil was chosen for the well-watered treatment and the soil water deficit treatment, respectively, corresponding to a soil water potential of $-0.01 \mathrm{MPa}$ and $-6 \mathrm{Mpa}$, respectively. Plants were randomised on the automated platform on a daily basis. Seeds of the same age were used for all genotypes and watering was carried out daily at the same time to avoid biases. Per genotype, 18 seedlings were grown in the well-watered and the water deficit treatments. The plants were allowed to develop for approximately 1 month and harvested when leaf 4 was fully mature and no longer increased in length. Several parameters were determined from leaf 4 , which is the first leaf growing autonomously by photosynthesis assimilation and independently of kernel storage. The few plants with more than a 5-day delay in leaf 4 appearance were not used or did not germinate, hence, 12 to 18 plants per genotype and treatment were analysed. The length of leaf 4 was measured daily from the base of the plant to the leaf tip and from its appearance until its harvest to determine the leaf growth rate (expressed in $\mathrm{mm} / \mathrm{h}$ ) as (L5-L1)/(Tp5-Tp1), where L1 and $\mathrm{L} 5$ are the lengths of leaf 4 measured in $\mathrm{mm}$ at time point (Tp) 1 and 5 , respectively. To compare the growth performance between the genotypes, the reduction percentage in the growth rate of leaf 4 under the water deficit condition was determined per genotype as follows: (average leaf growth rate under well-watered condition - average leaf growth rate under water deficit condition) / (average leaf growth rate under well-watered condition) ${ }^{*} 100$. The endpoint parameters measured upon harvesting include final blade weight, final blade and sheath weight, final blade width and total area of leaf 4 and the total plant biomass and the total plant dry weight.

\section{Data analysis}

\section{Seed yield and yield-associated parameters}

Statistical data analysis for the seed yield and yield-associated parameters was carried out with the Student's $t$-test. $P$ values were corrected for multiple testing with the Bonferroni correction (supplementary Table S2).

\section{Arabidopsis mild drought stress experiment}

Statistical data analysis was carried out for the final shoot areas measured in the Arabidopsis mild drought stress experiment on the WIWAM automated platform with the aim to determine the different effects upon mild drought stress of each transgenic line when compared to the control line. A two-way analysis of variance was conducted for the shoot area variable. The model included the factors genotype and treatment and the interaction term. When the interaction term was significant at the $5 \%$ significance level, Wald tests were performed to estimate the significance of the difference in effect upon water deficit of each genotype versus the control genotype. $P$ values were adjusted for multiple testing with Sidak step-down as implemented in the SAS software (Version 9.4 of the SAS System for Windows 7 64bit; Copyright (C) 2002-2012 SAS Institute Inc. Cary, NC, USA; www.sas.com). The analysis was done with the GLM procedure and correction for multiple testing of the interaction effect with the MULTTEST procedure.

\section{Maize mild drought stress experiment}

All the endpoint growth parameters measured in the mild drought stress experiments were analysed statistically with the aim to determine the different effects upon water deficit of each transgenic line compared to the control line as described for Arabidopsis except that family-wise error rates were calculated based on the maxT procedure as implemented in SAS.

\section{Acknowledgments}

We would like to thank Martine De Cock for help in preparing the manuscript. This research was funded by the European Union's Horizon 2020 Research and Innovation Programme (Grant No 731013). E.N. was awarded a PhD fellowship by the Flemish Interuniversity Council-University Development Cooperation-International PhD Programmes (VLIR-UOSICPPhD). S.D. is a postdoctoral fellow of the Research Foundation-Flanders.

\section{References}

ADAMS-PHILLIPS, L., BRIGGS, A.G. and BENT, A.F. (2010). Disruption of poly (ADP-ribosyl) ation mechanisms alters responses of Arabidopsis to biotic stress. Plant Physiol 152: 267-280.

ADAMS-PHILLIPS, L., WAN, J., TAN, X., DUNNING, F.M., MEYERS, B.C., MICHELMORE, R.W. and BENT, A.F. (2008). Discovery of ADP-ribosylation and other plant defense pathway elements through expression profiling of four different Arabidopsis--Pseudomonas R-avr interactions. Mol Plant-Microbe Interact 21 : 646-657. 
ALONSO-BLANCO, C., EL-DIN EL-ASSAL, S., COUPLAND, G. and KOORNNEEF, M. (1998). Analysis of natural allelic variation at flowering time loci in the Landsberg erecta and Cape Verde Islands ecotypes of Arabidopsis thaliana. Genetics 149: $749-764$

AMOR, Y., BABIYCHUK, E., INZÉ, D. and LEVINE, A. (1998). The involvement of poly(ADP-ribose) polymerase in the oxidative stress responses in plants. FEBS Lett 440: 1-7.

ANAMI, S., NJUGUNA, E., COUSSENS, G., AESAERT, S. and VAN LIJSEBETTENS, M. (2013). Higher plant transformation: principles and molecular tools. Int J Dev Biol 57: 483-494.

BARTSCH, M., GOBBATO, E., BEDNAREK, P., DEBEY, S., SCHULTZE, J.L., BAUTOR, J. and PARKER, J.E. (2006). Salicylic acid-independent ENHANCED DISEASE SUSCEPTIBILITY1 signaling in Arabidopsis immunity and cell death is regulated by the monooxygenase FMO1 and the Nudix hydrolase NUDT7. Plant Cell 18: 1038-1051.

BESSMAN, M.J., FRICK, D.N. and O'HANDLEY, S.F. (1996). The MutT proteins or "Nudix" hydrolases, a family of versatile, widely distributed,"housecleaning" enzymes. J Biol Chem 271: 25059-25062.

CHRISTENSEN, A.H., SHARROCK, R.A. and QUAIL, P.H. (1992). Maize polyubiquitin genes: structure, thermal perturbation of expression and transcript splicing, and promoter activity following transfer to protoplasts by electroporation. Plant Mol Biol 18: 675-689.

CLAEYS, H. and INZÉ, D. (2013). The agony of choice: how plants balance growth and survival under water-limiting conditions. Plant Physiol 162: 1768-1779.

CLAEYS, H., VAN LANDEGHEM, S., DUBOIS, M., MALEUX, K. and INZÉ, D. (2014). What is stress? Dose-response effects in commonly used in vitro stress assays. Plant Physiol 164: 519-527.

CLAUW, P., COPPENS, F., DE BEUF, K., DHONDT, S., VAN DAELE, T., MALEUX, K., STORME, V., CLEMENT, L., GONZALEZ, N. and INZÉ, D. (2015). Leaf responses to mild drought stress in natural variants of Arabidopsis. Plant Physiol 167: 800-816. [Erratum Plant Physiol 168: 1180].

CLOUGH, S.J. and BENT,A.F. (1998). Floral dip: a simplified method for Agrobacteriummediated transformation of Arabidopsis thaliana. Plant J 16: 735743.

COUSSENS, G., AESAERT, S., VERELST, W., DEMEULENAERE, M., DE BUCK, S., NJUGUNA, E., INZÉ, D. and VAN LIJSEBETTENS, M. (2012). Brachypodium distachyon promoters as efficient building blocks for transgenic research in maize. $J$ Exp Bot 63: 4263-4273.

D'AMOURS, D., DESNOYERS, S., D'SILVA, I. and POIRIER, G.G. (1999). Poly(ADP. ribosyl)ation reactions in the regulation of nuclear functions. Biochem $J$ 342: 249-268.

DE BLOCK, M., VERDUYN, C., DE BROUWER, D. and CORNELISSEN, M. (2005). Poly(ADPribose) polymerase in plants affects energy homeostasis, cell death and stress tolerance. Plant J 41: 95-106.

DOUCET-CHABEAUD, G., GODON, C., BRUTESCO, C., DE MURCIA, G. and KAZMAIER, M. (2001). lonising radiation induces the expression of $P A R P-1$ and PARP-2 genes in Arabidopsis. Mol Genet Genomics 265: 954-963.

DUNN, C.A., O'HANDLEY, S.F., FRICK, D.N. and BESSMAN, M.J. (1999). Studies on the ADP-ribose pyrophosphatase subfamily of the Nudix hydrolases and tentative identification of $\operatorname{trg} B$, a gene associated with tellurite resistance. J Biol Chem 274: 32318-32324

FENG, B., LIU, C., DE OLIVEIRA, M.V.V., INTORNE, A.C., LI, B., BABILONIA, K., DE SOUZA FILHO, G.A., SHAN, L. and HE, P. (2015). Protein poly(ADP-ribosyl) ation regulates Arabidopsis immune gene expression and defense responses. PLoS Genet 11: e1004936.

GE, L.-F., CHAO, D.-Y., SHI, M., ZHU, M.-Z., GAO, J.-P. and LIN, H.-X. (2008). Overexpression of the trehalose-6-phosphate phosphatase gene OsTPP1 confers stress tolerance in rice and results in the activation of stress responsive genes. Planta 228: 191-201.

GE, X., LI, G.-J., WANG, S.-B., ZHU, H., ZHU, T., WANG, X. and XIA, Y. (2007) AtNUDT7, a negative regulator of basal immunity in Arabidopsis, modulates two distinct defense response pathways and is involved in maintaining redox homeostasis. Plant Physiol 145: 204-215.

HALLAUER, A.R., LAMKEY, K.R. and WHITE, P.R. (1997). Registration of five inbred lines of maize: B102, B103, B104, B105, and B106. Crop Sci 37: 1405-1406.

HOOD, E.E., HELMER, G.L., FRALEY, R.T. and CHILTON, M.-D. (1986). The hypervirulence of Agrobacterium tumefaciens A281 is encoded in a region of pTiBo542 outside of T-DNA. J Bacteriol 168: 1291-1301.

ISHIKAWA, K., OGAWA, T., HIROSUE, E., NAKAYAMA, Y., HARADA, K., FUKUSAKI E., YOSHIMURA, K. and SHIGEOKA, S. (2009). Modulation of the poly(ADP-ribosyl) ation reaction via the Arabidopsis ADP-ribose/NADH pyrophosphohydrolase, AtNUDX7, is involved in the response to oxidative stress. Plant Physiol151:741-754

ISHIKAWA, K., YOSHIMURA, K., HARADA, K., FUKUSAKI, E., OGAWA, T., TAMOI M. and SHIGEOKA, S. (2010). AtNUDX6, an ADP-ribose/NADH pyrophosphohydrolase in Arabidopsis, positively regulates NPR1-dependent salicylic acid signaling. Plant Physiol 152: 2000-2012.

JAMBUNATHAN, N. and MAHALINGAM, R. (2006). Analysis of Arabidopsis Growth Factor Gene 1 (GFG1) encoding a nudix hydrolase during oxidative signaling. Planta 224: 1-11

JAMBUNATHAN, N., PENAGANTI, A., TANG, Y. and MAHALINGAM, R. (2010). Modulation of redox homeostasis under suboptimal conditions by Arabidopsis nudix hydrolase 7. BMC Plant Biol 10: 173.

KARIMI, M., DEPICKER, A. and HILSON, P. (2007a). Recombinational cloning with plant Gateway vectors. Plant Physiol 145: 1144-1154.

KARIMI, M., INZÉ, D., VAN LIJSEBETTENS, M. and HILSON, P. (2013). Gateway vectors for transformation of cereals. Trends Plant Sci 18: 1-4.

KIM, M.Y., ZHANG, T. and KRAUS, W.L. (2005). Poly(ADP-ribosyl)ation by PARP-1: 'PAR-laying' NAD+ into a nuclear signal. Genes Dev 19: 1951-1967.

KRASZEWSKA, E. (2008). The plant Nudix hydrolase family. Acta Biochim Pol 55 663-671.

LI, G., NASAR, V., YANG, Y., LI, W., LIU, B., SUN, L., LI, D. and SONG, F. (2011). Arabidopsis poly(ADP-ribose) glycohydrolase 1 is required for drought, osmotic and oxidative stress responses. Plant Sci 180: 283-291.

MURASHIGE, T. and SKOOG, F. (1962). A revised medium for rapid growth and bio assays with tobacco tissue cultures. Physiol Plant 15: 473-497.

NELISSEN, H., RYMEN, B., JIKUMARU, Y., DEMUYNCK, K., VAN LIJSEBETTENS M., KAMIYA, Y., INZÉ, D., and BEEMSTER, G.T.S. (2012). A local maximum in gibberellin levels regulates maize leaf growth by spatial control of cell division. Curr Biol 22: 1183-1187.

OGAWA, T., ISHIKAWA, K., HARADA, K., FUKUSAKI, E., YOSHIMURA, K. and SHIGEOKA, S. (2009). Overexpression of an ADP-ribose pyrophosphatase, AtNUDX2, confers enhanced tolerance to oxidative stress in Arabidopsis plants. Plant J 57: 289-301.

OGAWA, T., MURAMOTO, K., TAKADA, R., NAKAGAWA, S., SHIGEOKA, S. and YOSHIMURA, K. (2016). Modulation of NADH levels by Arabidopsis Nudix hydrolases, AtNUDX6 and 7, and the respective proteins themselves play distinct roles in the regulation of various cellular responses involved in biotic/abiotic stresses. Plant Cell Physiol 57: 1295-1308.

OGAWA, T., UEDA, Y., YOSHIMURA, K. and SHIGEOKA, S. (2005). Comprehensive analysis of cytosolic Nudix hydrolases in Arabidopsis thaliana. J Biol Chem 280 25277-25283.

OGAWA, T., YOSHIMURA, K., MIYAKE, H., ISHIKAWA, K., ITO, D., TANABE, N. and SHIGEOKA, S. (2008). Molecular characterization of organelle-type Nudix hydrolases in Arabidopsis. Plant Physiol 148: 1412-1424.

ROSSI, L., DENEGRI, M., TORTI, M., POIRIER, G.G. and SCOVASSI, A.I. (2002) Poly (ADP-ribose) degradation by post-nuclear extracts from human cells. Biochimie 84: 1227-1233.

SCHULZ,P., JANSSEUNE, K., DEGENKOLBE, T., MÉRET, M., CLAEYS, H., SKIRYCZ, A., TEIGE, M., WILLMITZER, L. and HANNAH, M.A. (2014). Poly(ADP-ribose) polymerase activity controls plant growth by promoting leaf cell number. PLOS ONE 9: e90322.

SCHULZ, P., NEUKERMANS, J., VAN DER KELEN, K., MÜHLENBOCK, P., VAN BREUSEGEM, F., NOCTOR, G., TEIGE, M., METZLAFF, M. and HANNAH, M.A (2012). Chemical PARP inhibition enhances growth of Arabidopsis and reduces anthocyanin accumulation and the activation of stress protective mechanisms. PLOS ONE 7: e37287.

SKIRYCZ, A., VANDENBROUCKE, K., CLAUW, P., MALEUX, K., DE MEYER, B. DHONDT, S., PUCCI, A., GONZALEZ, N., HOEBERICHTS, F., TOGNETTI, V.B., GALBIATI, M., TONELLI, C., VAN BREUSEGEM, F., VUYLSTEKE, M. and INZÉ, D. (2011). Survival and growth of Arabidopsis plants given limited water are not equal. Nat Biotechnol 29: 212-214.

SONG, J., KEPPLER, B.D., WISE, R.R. and BENT, A.F. (2015). PARP2 is the predominant poly(ADP-ribose) polymerase in Arabidopsis DNA damage and immune 
responses. PLoS Genet 11: e1005200.

VANDAELE, I., GONZALEZ, N., VERCAUTEREN, I., DESMET, L., INZÉ, D., ROLDÁNRUIZ, I. and VUYLSTEKE, M. (2012). Acomparative study of seed yield parameters in Arabidopsis thaliana mutants and transgenics. Plant Biotechnol J 10: 488-500.

YOSHIMURA, K. and SHIGEOKA, S. (2015). Versatile physiological functions of the Nudix hydrolase family in Arabidopsis. Biosci Biotechnol Biochem 79: 354-366.

YOSHIMURA, K., OGAWA, T., UEDA, Y. and SHIGEOKA, S. (2007). AtNUDX1, an 8-oxo-7, 8-dihydro-2'-deoxyguanosine 5'-triphosphate pyrophosphohydrolase, is responsible for eliminating oxidized nucleotides in Arabidopsis. Plant Cell Physiol 48: 1438-1449.

ZHANG, H., GU, Z., WU, Q., YANG, L., LIU, C., MA, H., XIA, Y. and GE, X. (2015). Arabidopsis PARG1 is the key factor promoting cell survival among the enzymes regulating post-translational poly(ADP-ribosyl)ation. Sci Rep 5: 15892.

ZIMMERMANN, P., HIRSCH-HOFFMANN, M., HENNIG, L. and GRUISSEM, W. (2004). GENEVESTIGATOR. Arabidopsis microarray database and analysis toolbox. Plant Physiol 136: 2621-2632. 


\section{Further Related Reading, published previously in the Int. J. Dev. Biol.}

Interactions among gibberellins, brassinosteroids and genes regulate stomatal development in the Arabidopsis hypocotyl Diego González, Sonia Fuentes and Laura Serna

Int. J. Dev. Biol. (2017) 61: 383-387

https://doi.org/10.1387/ijdb.170021LS

\section{Biotechnology of nutrient uptake and assimilation in plants}

Damar L. López-Arredondo, Marco A. Leyva-González, Fulgencio Alatorre-Cobos and Luis Herrera-Estrella

Int. J. Dev. Biol. (2013) 57: 595-610.

https://doi.org/10.1387/ijdb.130268lh

Higher plant transformation: principles and molecular tools

Sylvester Anami, Elizabeth Njuguna, Griet Coussens, Stijn Aesaert and Mieke Van Lijsebettens

Int. J. Dev. Biol. (2013) 57: 483-494

https://doi.org/10.1387/ijdb.130232mv

Multi-probe in situ hybridization to whole mount Arabidopsis seedlings

Leonardo Bruno, Antonella Muto, Natasha D. Spadafora, Domenico laria, Adriana Chiappetta,

Mieke Van Lijsebettens and Maria B. Bitonti

Int. J. Dev. Biol. (2011) 55: 197-203

https://doi.org/10.1387/ijdb.103132lb

\section{Evolution and pleiotropy of TRITHORAX function in Arabidopsis}

Zoya Avramova

Int. J. Dev. Biol. (2009) 53: 371-381

https://doi.org/10.1387/ijdb.082664za

Lessons from a search for leaf mutants in Arabidopsis thaliana

José Manuel Pérez-Pérez, Héctor Candela, Pedro Robles, Víctor Quesada, María Rosa Ponce and José Luis Micol

Int. J. Dev. Biol. (2009) 53: 1623-1634

https://doi.org/10.1387/ijdb.072534jp

Arabidopsis monomeric G-proteins, markers of early and late events in cell differentiation Mariette Bedhomme, Chantal Mathieu, Amada Pulido, Yves Henry and Catherine Bergounioux Int. J. Dev. Biol. (2009) 53: 177-185

https://doi.org/10.1387/ijdb.072488mb

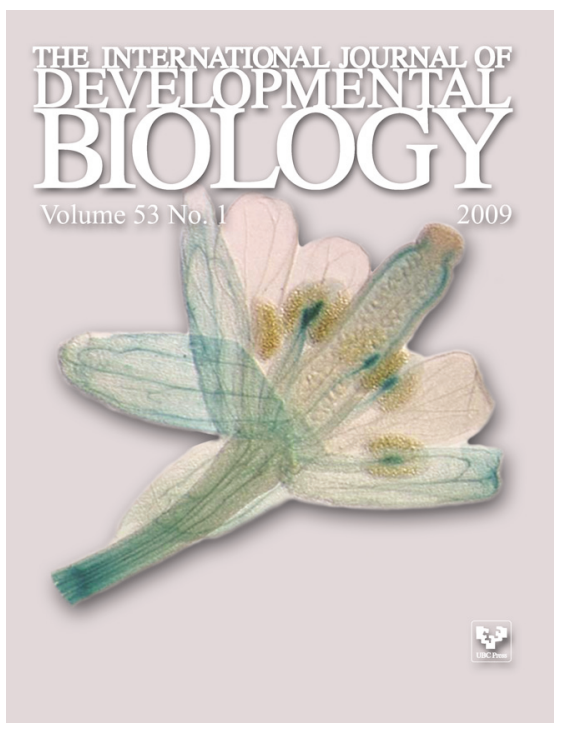

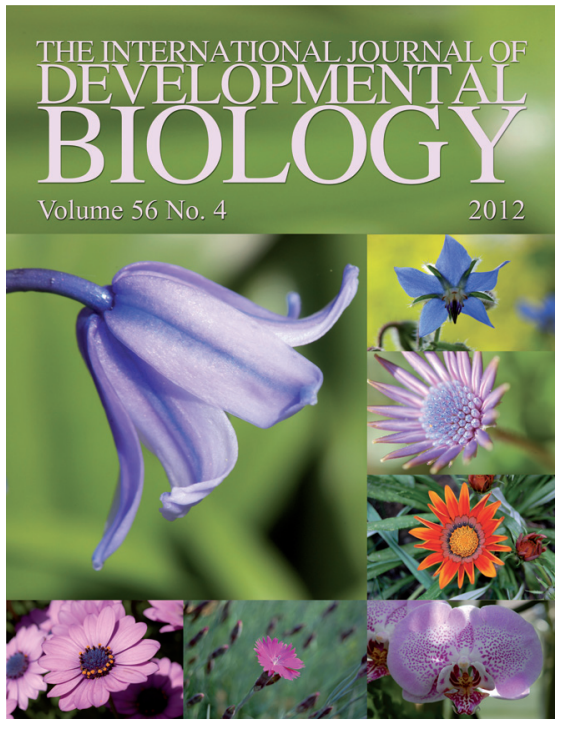
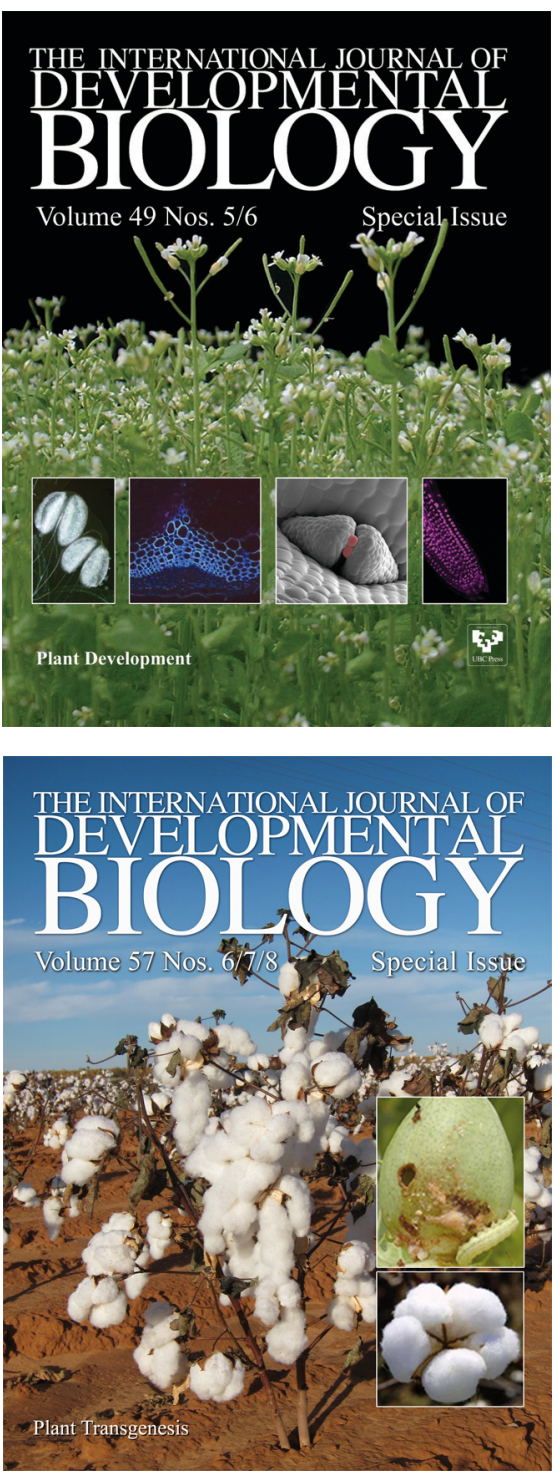